\title{
Recent Work on Vitamin A.
}

URING the past two years advances have been made in our knowledge of the chemistry and properties of vitamin A and its relationship to certain other compounds, but progress, though steady, has not been so dramatic as in the case of vitamin $D$. Attention has been directed chiefly to methods of assay, both biological and chemical, to attempts at isolation of the vitamin, and to its formation under natural conditions : less work has been devoted to its physiological functions. In this article certain aspects of the subject will be briefly reviewed.

Assay.

The tediousness and inherent difficulties of the biological test have led investigators to seek some simple chemical reaction or some physical property which could be utilised for the quantitative determination of the vitamin. However, since these methods are not absolutely specific, the final criterion must be the animal test, so that its accuracy has been critically considered and its technique improved, in the hope of obtaining more reliable results.

The arsenic trichloride test of Rosenheim and Drummond (Biochem.J., vol. 19, p. $753 ; 1925$ ) and the antimony trichloride test of Carr and Price (ibid., vol. 20 , p. 497 ; 1926) have been widely used; more especially the latter, since the blue colour produced lasts somewhat longer than that given by the former reagent. Certain precautions have to be observed in carrying out the test, since the proportionality between the amount of vitamin A containing oil taken and the blue colour developed is not linear except possibly over a small range of concentrations. It is necessary, therefore, to find the amount of oil which will give a standard depth of colour; since the blue is usually mixed with other colours, it is most conveniently measured in Lovibond tintometer units. It is also essential to standardise the reagents and the temperature: the amount of oil present influences both the rate of development and of fading of the colour (N. Evers, Quart. J. Pharmacy and Pharmacol., vol. 2, p. 227 ; 1929. T. T. Cocking, ibid., p. 310 : E. R. Norris and I. S. Danielson, J. Biol. Chem., vol. 83 , p. 469 ; 1929). With cod-liver oil, good agreement has been obtained between the colorimetric and biological methods, but the presence in animal fats of other substances giving the blue colour with antimony trichloride interferes with the direct quantitative estimation of the vitamin. Thus both carotin and xanthophyll give a deep permanent blue under the conditions of the test. Willimott and Wokes (Lancet, vol. 2 , p. 8 ; 1927) removed the interfering pigments by adsorption on charcoal, and found good agreement between the two methods of assay in the case of a variety of vegetable and animal foodstuffs. The blue colour can be distinguished also by spectroscopic examination : thus in the case of vitamin $A$ with the $\mathrm{AsCl}_{3}$ reagent, there is a band at $5870 \mathrm{~A}$., with a second band, developing on standing, at $4750 \mathrm{~A}$.; with the $\mathrm{SbCl}_{3}$ reagent the initial band is at $6140 \mathrm{~A}$. and the second at $5300 \mathrm{~A}$. : in both cases the initial bands rapidly fade. Carotin, however, gives a band at $5900 \mathrm{~A}$. and the colour produced is duller and greener (Rosenheim and Drummond, loc. cit.; Wokes, Biochem. J., vol. 22, p. 997 ; 1928. Moore, Lancet, vol. 2 , p. 219 ; 1929). Blue colours are also given by other compounds, but under conditions in which they are not likely to be confused with that given by vitamin A: thus both cholesterol and cholic acid, after treatment with benzoyl chloride in solution in chloroform, give a blue colour with $\mathrm{AsCl}_{3}$ (Rosenheim, Biochem. J., vol. 21, p. 386 ; 1927. Wokes, ibid., vol. 22 , p. $830 ; 1928)$. The cholesterol oxidation product has none of the properties of vitamin A, fails to give the colour after solution in oil, and has no stimulating effect on growth.

The absorption spectrum of cod-liver oil shows bands at 3200-3280 A. and 2700-2900 A. Morton and Heilbron (Biochem. J., vol. 22, p. 987 ; 1928) have found that the intensity of the former band varies with the intensity of the blue colour developed in the $\mathrm{SbCl}_{3}$ test, both in natural oils and concentrates, and also in oils oxidised or irradiated when the band disappears and no blue colour is obtained. Other compounds may show a band near $3200 \mathrm{~A}$. : their presence is disclosed after oxidation of the oil. Although the intensity of this band may, under certain conditions, be used as an estimate of the concentration of vitamin $A$ in the oil, yet it is not absolutely specific for the vitamin, so that it cannot be relied on as sole test, without an accompanying biological assay, in the case of materials from which the presence of interfering substances has not been excluded. Rosenheim and Webster (ibid., vol. 23 , p. 633 ; 1929 ) have, in fact, shown that dehydroergosterol has an absorption band at 3200-3280 A., but gives no blue colour with $\mathrm{AsCl}_{3}$ or $\mathrm{SbCl}_{3}$, and is inactive in doses up to $1 \mathrm{mgm}$. per diem when given to rats maintained on the standard deficient diet. The intensity of the band, however, is considerably less than that of the absorbing substance in cod-liver oil.

A number of workers have analysed the responses of their animals, the growth of which had ceased on a vitamin A deficient diet, to various supplements containing the vitamin. It is now agreed that such a diet must contain vitamin $D$, and that results obtained on diets deficient in both vitamins $A$ and $D$ cannot be relied on to give even a rough idea of the vitamin A activity. One of the difficulties of the usual method of assay is that when growth ceases the rat is frequently suffering from some infection, and that a supply of vitamin A may fail to stimulate growth until the infection has cleared up, or if the dose is too small, the animal may succumb to its infection. Coward and Key (ibid., vol. 22 , p. $1019 ; 1928$ ) find that the responses of depleted animals fall into four groups: there may be no response, on too small a dose ; there may be subnormal quantitative growth, with or without premature slackening, on a small dose ; or there may be normal growth, with premature slackening or to maturity, according to the size of the dose given. Sometimes a growth response only occurs after a latent period of some weeks. They consider it necessary to use 2-4 animals on each dose with a test period of 8 weeks. Hume and Smith (ibid., vol. 22, p. 504; 1928 ) report similar results : they are of opinion that it is possible to obtain a qualitative result by this method, and possibly in the first 3-4 weeks of vitamin A feeding after a depletion period, to attain a quantitative assay. They consider that a better method is to give the animals small doses of vitamin from the beginning of the experiment : the growth curves are graded according to the size of the dose, but a result cannot be looked for in under 3 months.

Drummond and Morton (ibid., vol. 23, p. 785 ; 1929 ) found the growth responses of different animals on the same doses to vary considerably: up to twelve animals on each dose, with an extensive range of doses, must be used to obtain a distinction between two cod-liver oils differing from each other by less than 100 per cent. Only the growth rates for the first 5-6 weeks following the depletion period should be considered : better results are obtained when doses necessary to give a growth rate of 3 grams per week 
are compared than when comparison is made between rates of growth on the same dose. These authors hold, however, that for quantitative estimation of vitamin $A$ in cod-liver oil, the colour test or the determination of the intensity of the absorption band gives more reliable results than the biological assay. Similar analyses have been published by Nelson and Jones, and Sherman and Burtis (J. Biol. Chem., vol. 80, p. 215 , and vol. 78 , p. 671 ; 1928). Smedley-Maclean and her co-workers (Biochem. $J$., vol. 23, p. 634; 1929 ) suggest that doses of the substance under test which will just sustain life over a certain time, and those which just fail to do so, should be determined, since a better comparison between different samples can be made thus. Furthermore, as a check upon the response of the animal, a dose of cod-liver oil which might be expected to stimulate growth should be given at the end of the experiment.

In connexion with biological assays, some recent work by Coward and her collaborators may be referred to (Coward et al., Biochem. J., vol. 23, pp. 695 and 913 ; 1929). Rats sometimes fail to grow on an apparently complete synthetic diet; the failure has been traced to the casein employed, since changing the casein permits of normal growth. This work may explain some of the irregular results which are observed at different times in vitamin $\mathbf{A}$ (and B) assay.

\section{Chemistry.}

Drummond and Baker (Biochem. J., vol. 23, p. $274 ; 1929$ ) have investigated the chemical nature of vitamin A. Unsaponifiable matter was prepared from the liver oils of the cod, sheep, and Greenland and Japanese sharks. Cholesterol was removed by crystallisation : only small amounts were present in the shark liver oils, the chief constituents being selachyl, batyl, chimyl, and oleyl alcohols, some of which were removed in part by crystallisation from suitable solvents. The residual oils were then submitted to fractional distillation at very low pressures: no satisfactory fractionation was obtained in the case of codor sheep-liver oils, and in both cases decomposition occurred : recovery of the vitamin from the fractions was only 2 and 11 per cent respectively, as estimated by the colour test. Distillation of the shark-liver oils yielded only the higher alcohols, but the vitamin recovery was up to 50 per cent in the case of the Japanese shark-liver oil. It is considered that the destruction of the vitamin in the former case is due to the presence of complex alcohols and hydrocarbons of the terpene series, which are only present in small proportions in the shark oils. No fraction consisting exclusively of vitamin A was obtained, nor was it separated by crystallisation. It appears that it is present in Japanese shark-liver oil to the extent of 1 per cent only, or less, of the unsaponifiable matter. The authors are of opinion that it is probably a sterol, from the nature of its colour reactions, and suggest that its chemical composition may be elucidated rather by studying the properties of sterols than by attempting its isolation from a natural source.

In connexion with the destruction occurring on distillation at low pressures, it may be mentioned that Wokes and Willimott (ibid., vol. 21 , p. 419 ; 1927) suggest, as a result of experiments on the effect of heat and oxidation on the vitamin A content of codliver oil, that the destruction observed may be due to the presence of volatile organic peroxides.

In the identification of the complex alcohols present in liver oils, it is often necessary to hydrogenate the material and isolate the reduced products. Drummond and Baker (loc. cit.) found that reduction of the oil obtained from the unsaponifiable matter of codliver oil, after removal of sterols by digitonin, did not destroy completely the vitamin A content, but the reduction was admittedly incomplete. Nakamiya and Kawakami (Sci. Papers, Inst. Physical and Chem. Res., vol. 7 , p. $121 ; 1927)$, however, found that hydrogenation of 'Biosterin' led to complete loss of the vitamin activity.

Another line of approach to the chemical nature of vitamin A has been the study of its relationship to certain plant pigments. Xanthophyll has been shown to have no growth-promoting power (Willimott and Moore, Biochem. J., vol. 21, p. 86 ; 1927 : SmedleyMaclean et al., ibid., vol. 23 , p. 634 ; 1929), but several observers (v. Euler, Maclean, Moore) have found that carotin in very small doses can restore normal growth in a rat maintained on a vitamin $A$ deficient diet.

Collison, Hume, Smedley-Maclean, and Smith (Biochem. J., vol. 23, p. 634) have investigated the nature of the vitamin A constituent of certain green leaves.

The material soluble in light petroleum was extracted from green cabbage and saponified : the yield was 0.84 per cent of the dried leaves. The unsaponifiable matter was fractionated by means of solvents : cold alcohol extracted a sterol together with a substance giving the blue colour with antimony trichloride: hot alcohol extracted from the residue nonacosane and di- $n$-tetradecyl ketone: whilst from the final material carotin was obtained by extraction with light petroleum: the carotin had definite growth-promoting power even in a daily dose of $0.003 \mathrm{mgm}$. From white cabbage little carotin was obtained, and this material contained little vitamin A. Carotin prepared from spinach and carrots was also active, in doses of $0.01 \mathrm{mgm}$. daily, but it was obtained in a somewhat less pure condition than when cabbage was used as source. The authors consider that possibly more than one substance can function as vitamin $A$, that, in fact, the growth-promoting power is the property of a special grouping of atoms which may occur in several different molecules: they cite the observations of v. Euler and his co-workers, who have shown that dihydro- $a$-crocetin is also active. Moreover, the absorption spectra of the blue colours produced by vitamin $\mathrm{A}$ and carotin with $\mathrm{SbCl}_{3}$ are different, but no trace of the former appears in that of an active sample of carotin, suggesting that vitamin $A$ is not simply a contaminant of the latter. It is possible that the negative results of Drummond as regards the potency of carotin are due to the fact that his basal diet is free from fat. There is evidence that some constituent of the unsaponifiable fraction of the fat is necessary for carotin to exert its growth-promoting power.

Moore has also found that carotin can exert a vitamin A activity (Biochem. $J$., vol. 23 , p. 803 ; 1929 : Lancet, vol. 2, p. 380 ; 1929). His results confirm those obtained by other workers, who have found carotin active, but his latest experiments have led to a different conclusion. Carotin was fed to rats in daily doses of from 0.0001 to $0.75 \mathrm{mgm}$.; after 5 weeks the animals were killed, the fat extracted from the liver and analysed for vitamin A by colorimetric and spectroscopic methods. The intensity of the vitamin $A$ blue reaction (absorption band at 6100 . $6300 \mathrm{~A}$.) indicated that a daily dose of $0.01 \mathrm{mgm}$. or more of carotin increased the vitamin A content of the liver : at the same time only a very slight increase in the degree of yellow pigmentation of the fat occurred, showing that carotin was stored to only a negligible extent in this organ. Hence, even when a large excess is ingested, carotin appear's in the liver only in minute traces; the simplest explanation of the increase in the vitamin A content is that it was actually formed from a portion of the carotin eaten.

In a recent review Drummond points out that the

No. 3150 , Vou. 125] 
ordinary standards of chemical purity give insufficient security in biochemical work with substances so highly active as the vitamins (Chem. and Industry, vol. 49 , p. $1 \mathrm{~T} ; 1930)$. The difficulties experienced in detecting ergosterol as the impurity in cholesterol which is activated by exposure to ultra-violet light need scarcely be referred to in this connexion. In this case, the doubt is as to the purity of the carotin used by the various investigators who have found it to contain growth-promoting activity. Drummond has obtained carotin of melting point so high as $185^{\circ}$ : it showed no vitamin A activity even in relatively large doses. He has also prepared di-hydro-a-crocetin: his specimen failed to restore growth in rats deprived of vitamin A. From the results obtained with liver oils, it may be estimated that the daily dose of the vitamin for a rat is probably less than $0.0001 \mathrm{mgm}$., an order of activity comparable with that of vitamin D. If this is so, preparations of vitamin A which must be given in larger doses to restore growth must necessarily be impure.

\section{Physiology.}

The presence of vitamin $\mathrm{A}$ in the diet is essential if it is to be adequate for growth and the maintenance of normal health. E. Mellanby has stressed the latter function: without vitamin $\mathrm{A}$ in the food, infections occur regularly among the experimental animals: administration of large quantities to human beings may cure certain infections (see NATURE, vol. 122, p. 750 ; 1928). It must be assumed that vitamin $\mathrm{A}$ is, or is the precursor of, an essential constituent of certain cells of the body : without it they can neither multiply nor maintain their normal structure. In many cases the onset of an infection appears to be facilitated by an alteration in the cells lining an exposed surface when the vitamin is withdrawn from the diet.

Unlike vitamin $D$, vitamin $A$ is not synthesised in the animal body : hence it is important to see that it is present in the food. Thus the content of cow's milk in this vitamin depends on the food given the animal; it is increased by feeding green food and cod-liver oil. The vitamin $\mathrm{D}$ in the milk can be increased by giving it in the food or by irradiating the cow or even the milk itself.

Yeast, a source of many interesting compounds, does not contain vitamin A: previous conclusions to the contrary were the result of using a diet deficient in both vitamins $A$ and $D$ in testing for this vitamin. (Hurne, Smith, and Smedley-Maclean, Biochem. J., vol. 22 , p. $27 ; 1928$.)

The ultimate source of vitamin $\mathrm{A}$ is the green plant : there has been considerable doubt as to whether the presence of light is necessary for its formation or not, partly owing to the difficulty of excluding all light, partly owing to the fact that many tests have been carried out using a basal diet deficient in both vitamins $A$ and D. The most recent work indicates, however, that vitamin A can be formed in the complete absence of light, except the minimum required to feed and handle the animals and collect the etiolated shoots. Moore found that wheat seeds contained no vitamin $\mathbf{A}$, that etiolated shoots fed to rats in a diet containing vitamin $\mathrm{D}$ but no A stimulated growth, although given to the animals after dark, and finally that the same result was obtained. when no light except red was admitted to the room in which the animals were housed and the shoots grown throughout the experiment (ibid., vol. 21, p. $870 ; 1927$; vol. 22 , p. $1097 ; 1928)$. It is, however, possible that the brief exposure to the red light may have been the essential factor in the production of the vitamin : it is certain that light can accelerate the synthesis, since green plant tissues are better sources than white.

\section{Education and Science in the Civil Service Estimates.}

THE Civil Estimates and Estimates for Revenue 1. Departments (Vote on Account) for the year ending Mar. 31, 1931, have been issued (82. London: H.M. Stationery Office. 3d.net). The total of the estimates for the full year is $£ 368,095,208$, against a total of $£ 320,190,105$ voted for the current year; this latter total, however, includes supplementary estimates.

The items in which readers of NATURE will be most interested occur in Classes IV. and VI., and are as follows:

\begin{tabular}{|c|c|c|}
\hline & $\begin{array}{c}\text { Total } \\
\text { Estimate for } \\
1930 \text { (Net). }\end{array}$ & $\begin{array}{l}\text { Total Net } \\
\text { Estimate for } \\
1929 \text { (adjusted } \\
\text { for transfers). }\end{array}$ \\
\hline Class IV. & & \\
\hline Board of Education & $£ 45,495,653$ & $£ 4 ., 685,899$ \\
\hline British Museum . . & 297,263 & 283,559 \\
\hline $\begin{array}{l}\text { Scientific Investigation, } \\
\text { etc. }\end{array}$ & 232,303 & 228,278 \\
\hline $\begin{array}{l}\text { Universities and Col- } \\
\text { leges, Great Britain . }\end{array}$ & $1,830,000$ & $1,550,000$ \\
\hline $\begin{array}{l}\text { Scotrand : } \\
\text { Public Education . }\end{array}$ & $7,197,422$ & $6,173,485$ \\
\hline Class VI. & & \\
\hline $\begin{array}{l}\text { Ministry of Agriculture } \\
\text { and Fisheries }\end{array}$ & $2,312,310$ & $2,953,863$ \\
\hline Beet Sugar Subsidy, & & \\
\hline $\begin{array}{l}\text { Great Britain } \\
\text { Surveys of Great Britain }\end{array}$ & $\begin{array}{r}5,400,000 \\
\end{array}$ & $4,250,000$ \\
\hline Forestry Commission & $\begin{array}{l}143,200 \\
837,800\end{array}$ & 600,000 \\
\hline Development Fund & 625,000 & 300,000 \\
\hline Development Grants & 200,000 & 一 \\
\hline $\begin{array}{l}\text { Department of Scientifie } \\
\text { and Industrial Re- } \\
\text { search. }\end{array}$ & 469.278 & 446914 \\
\hline SCOTLAND : & & \\
\hline $\begin{array}{l}\text { Department of Agricul- } \\
\text { ture }\end{array}$ & & \\
\hline Fishery Board . & 137,442 & 68,895 \\
\hline
\end{tabular}

The details of Class IV. estimates are now available (83-IV. London: H.M.S.O. 1s. 3d. net). Under the heading "Scientific Investigation, etc.", there is an increase of $£ 4025$ over last year's estimate. The position is shown in the following table:

\begin{tabular}{|c|c|c|c|}
\hline Grants in AID. & 1930. & 1929. & Increase. \\
\hline Royal Society . . . & $£ 10,000$ & $£ 10,000$ & - \\
\hline Royal Geographical Society & 1,250 & 1,250 & - \\
\hline Royal Society of Fdinburgh & 600 & 600 & - \\
\hline British School at Athens . & 500 & 500 & - \\
\hline British School at Rome . & 500 & 500 & - \\
\hline \multicolumn{4}{|l|}{ Royal Scottish Geographical } \\
\hline Society . . . . & 200 & 200 & - \\
\hline National Library of Wales. & 25,334 & 25,333 & \\
\hline National Museum of Wales. & 28,000 & 27,000 & 1,000 \\
\hline Solar Physics Observatory . & 3,000 & 3,000 & \\
\hline \multicolumn{4}{|l|}{ North Sea Fisheries In- } \\
\hline Royal Academy of Music . & 500 & 500 & - \\
\hline Royal College of Music & 500 & 500 & - \\
\hline \multicolumn{4}{|l|}{ Royal Academy of Dramatic } \\
\hline Art . . . . & 500 & 500 & - \\
\hline British Academy . & 2,000 & 2,000 & - \\
\hline Central Library for Students & 3,000 & - & 3,000 \\
\hline Medical Research Council. & 148,000 & 148,000 & - \\
\hline \multirow{3}{*}{$\begin{array}{l}\text { OTHER GRaNTS. } \\
\text { Edinburgh Observatory }\end{array}$} & & & \\
\hline & 7,269 & 7,245 & 24 \\
\hline & 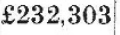 & 228,278 & 4,025 \\
\hline
\end{tabular}

No. 3150 , VoL. 125] 